Síntesis:

Todo poder echa mano del discurso delineando un dominio, sea este Estado-nación, Imperios clásicos,

sistema-mundo e Imperio como posibilidad única

de una nueva geopolítica planetaria. Desde el macroespacio y el poder que ordena y dice cómo debe ser pensado en donde el concepto de soberanía será la ficción instrumental que permita la obediencia a las leyes hasta entender que esta soberanía no es más que una simple ficción jurídica. Pero antes de eso se requiere comprender la génesis del Estado

y sus diferentes formas de capital que se acumulan,

distribuyen y determinan la posición de los agentes

dentro del espacio social dado, es decir, entre los

diferentes campos como una historia hecha cosa.

Esta particularidad propicia en los investigadores de lo político, la posibilidad de provocar fisuras críticas en estas grandes entelequias políticas.

Palabras clave: macroespacio, ficción jurídica, génesis del Estado, Estados derrumbados, geopolítica

critica.

Synthesis:

All power to seize speech outlining a domain, is this nation-state, Empires classical world system and Empire as unique opportunity for a new global geopolitics. Since macro espace and power that orders and said it should be thought of where the concept of sovereignty will be instrumental fiction that allows obedience to laws to understand that this sovereignty is nothing more than a simple legal fiction. But before that is required to understand the genesis of the state and its different forms of capital that accumulate, distribute and determine the position of staff within the social space given, several between fields as a story made thing. This feature facilitates investigators in politics,

the possibility of provoking criticims in these large cracks entelequia policies.

Key Words: macro espace, legal fiction, genesis of the State, collapsed States, geopolitical critici.

\section{La geografía política de los}

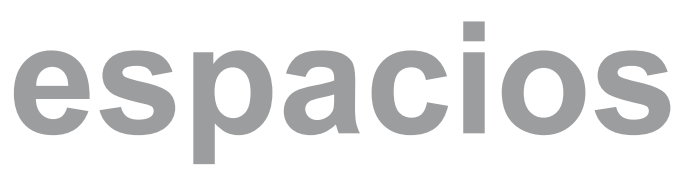

Gonzalo Ortiz Charry

Comunicador Social Periodista,

Magíster en Estudios políticos.

Docente investigador de la

Facultad de Ciencias de la Comunicación de Uniminuto

e-mail: goortiz@uniminuto.edu

Fecha de recepción: 13-05-08

Introducción

Fecha de aprobación: 24-06-08

"En aquel Imperio, el arte de la cartografía logró tal corrección que el mapa de una sola provincia ocupaba toda una ciudad, y el mapa del imperio, toda una provincia. Con el tiempo, estos mapas desmesurados no satisficieron y los colegios de cartógrafos levantaron un mapa del imperio, que tenía el tamaño del Imperio y coincidía puntualmente con él”. Jorge Luis Borges, "Del rigor en la Ciencia", en Historia Universal de la Infamia.

\section{Asumiendo que el espacio es uno de los fundamentos de la geografía física, el cual a su} vez, aporta contenido al canón académico de la geopolítica, lo cual podríamos interpretar como un espacio hecho discurso (poder), comunicación (propaganda) y pedagogía (símbolos patrios). Idea central que trataremos de desglosar para comprender la 
complejidad de este hilo conductor que sigue las formas que toma el espacio.

Cuando algunas ciencias políticas ven sus cimientos agrietados por catástrofes históricas, tomemos como paradigma el hundimiento de la geopolítica clásica alemana, el cual culmina en una hecatombe, asistimos a una nueva feria de eufemismos como "explosión-implosión", Brzezinski (1970); "espacios fluidos", Castell (2000); o "espacios poéticos" de Bachelard que, a partir de grandes construcciones teóricas, intentan atajar el hundimiento de la geopolítica como constructo teórico. Este formalismo "científico" y político que trata toda la historia espacial de la geopolítica clásica con sus grandes teóricos, Rudolf Kjellen, Friedrich Ratzel y Sir Halford Mackinder, desembocan en lo que se ha defininido como la primera etapa de la corriente geopolítica con su gran proyecto, el Tercer Reich.

Proyecto que continuará adoptando nuevas formas a partir del fin de la Segunda

Guerra Mundial, tenemos a una nueva geografía política de la Guerra Fría en nuestros días, en donde la humanidad queda sometida a la Pax Americana que hoy globaliza el espacio interior, es decir, desaparece la soberanía que había al interior de los Estados, lo que Bertrand Badie (2000:14) define como una "ficción desenmascarada". Ante lo cual el binomio Negri y Hardt (2000:202), presentan el espacio exterior como un nuevo "espacio estriado" donde la soberanía del Estado moderno ha mutado al "espacio liso" del Imperio, lo cual se constituye en una nueva forma de soberanía global que hace desaparecer las fronteras.

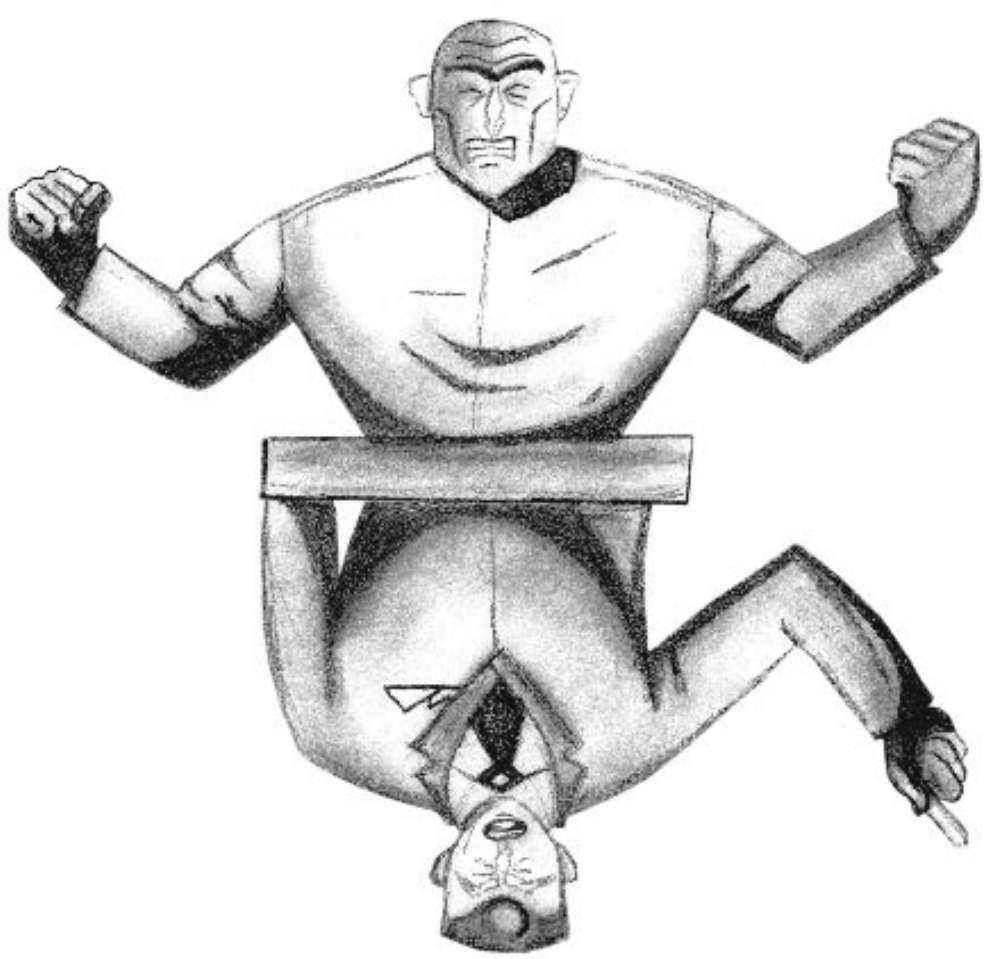

Hoy, la planetarización o mundialización despoja la geopolítica o geografía política de su antigua conflictividad, convirtiéndola en una simple mediación decisoria de los "intelectuales positivos", que toman las decisiones de acuerdo con un "código geopolítico" proveniente de un mando central, aparentemente indeterminado, que programa guerras puntuales sobre un mapamundi fijo e inmutable.

Simplicidad aparente que creemos, pone un velo sobre cualquier interpretación que se intente del fenómeno de la geopolítica en conexión con el espacio o una política de los espacios ligados a la tensión entre los discursos de las ideologías propietarias. Esta problemática puede 
reflejarse más en una ciencia física como la geografía, en donde aquello que originariamente parecían simples memorias de viajeros y bitácoras de geógrafos de todo tipo, hoy sucumbe ante una realidad en donde convergen una amplia y compleja variedad de espacios y semióticas, que la informática produce como data de espacios virtuales inaprensibles a todo ser humano, es decir, estamos incursionando en el descubrimiento de nuevos tipos de violencia simbólica.

Pretendemos de este ensayo, provocar unas fisuras críticas de estas grandes entelequias políticas.

Al mirar sobre el horizonte de las ciencias políticas encontramos un empobrecimiento de los conceptos, más cuando el corpus de las mismas está tensionado entre los extremos, por tanto, a partir de este estudio queremos, en primer lugar, determinar si es otra ideología más que apunta a un macroespacio o un subcampo del campo político, jurídico y mediático que se mueve de acuerdo con sus intereses $y$, ante todo, evaluar el papel que juega el campo científico como validador.

Además, resulta de primordial importancia ir en contravía al sentido común, en donde se inscribe la geopolítica como un asunto de fronteras, sea ampliación o rompimiento, por lo cual debemos en este proceso someter el espacio a un ejercicio de gobernabilidad como espacio discursivo que prepara una entrada a la analítica del poder ampliamente estudiada por Foucault, lo que lleva a la "deconstrucción del discurso" propuesta por John Agnew.

Para Kjellen y Ratzel el Estado era un organismo vivo en crecimiento rápido, de espacios dinámicos en continua expansión -sin fronteras naturales-, lo cual ha estado apoyado en razones demográficas y económicas de Imperio. Esto nos hace pensar que aquí se fomentan unas realidades fundamentadas en vacíos teóricos en torno a la teoría del Estado, esto genera cierta inquietud investigativa que trataremos de allanar. Será, por tanto, necesario trazar y mapear, una génesis histórica del Estado en la obra de Bourdieu, que nos permita ver cómo llega éste a producir geografías políticas de matices diversas para apropiarnos de nuevas herramientas como la geometría del espacio político que aporta las bases para entender apropiadamente la geopolítica como la percibimos hoy en día, sustentada en ideologías que devienen en una "ciencia" del dominio excluyente. Esto nos conduce, a través de estas teorías comunicantes, hasta la génesis del macroespacio que se instituye en el Estado-Nación.

Determinada la política de los macro-espacios y el papel que juega la gubernamentalidad como una microfísica del poder y la génesis del Estado a partir del estudio de los diferentes capitales que lo conforman, veremos cómo se precipitan éstos en el vórtice del "Estado derrumbado" en donde la concepción de soberanía nacional entra en crisis, en términos de Badie, al sostener que este concepto es una ficción jurídica.

Por último, acudimos a un caso práctico en donde se intentó crear variados tipos de espacios sujetos en un proyecto de reforma constitucional como alternativa de rompimiento a la propuesta geopolítica planetaria.

Pero, antes de comenzar esta "aventura teórica" y, a manera de advertencia, nos apoyaremos en Bachelard, quien enuncia que "la esencia misma de la reflexión es comprender que no se había comprendido"1. Por tanto, nos vemos obligados al ejercicio de desglosar cada uno de los ingredientes de esa mescolanza de ideologías que se acomodan de forma amorfa en todo el contenido del "discurso geopolítico". 


\section{Macro-espacio y Estado pensado}

Anteponer la cuestión del Estado antes que cualquier geografía política, no se hace por simple capricho, sino para esbozar un sistema expositivo tanto diacrónico como sincrónico. Así evitamos el dilema de muchos profesores que, en algún momento de su discurso, evaden la problemática del Estado u otros, a la manera de Peter J. Taylor, que tratan de enmendar el error de esta manera: "Hice un análisis de tipo descriptivo de la formación del mapa-político mundial. Es decir, me ha preocupado más el modo en que se ha originado el mapa, que por que tenía que existir un mapa de este tipo"2.

Sólo el origen del Estado puede dar explicaciones a la creación no sólo de un mapa, sino de todos los derivados adyacentes de su génesis, desarrollo y crisis. Esta amnesia de la génesis del Estado, asunto que trataremos más adelante, es la tierra propicia para las intersecciones de lo subjetivo con lo objetivo, o viceversa.

Resulta válido para esta investigación, como el profesor Taylor (1994) citando a Clark y Dear señala con una precisión contable que existen dieciocho teorías diferentes que se resumen en dos modos de análisis: teorías del Estado en el capitalismo y teorías del Estado capitalista. Para el mismo Taylor son las dos eternas visiones clásicas, la primera, se refiere a las teorías del Estado liberal o conservador y la segunda, a la súper estructura de las escuelas marxistas.

\footnotetext{
1 BACHELARD, Gastón, Epistemología. Textos escogidos por Dominique Lecourt, Barcelona, Editorial Anagrama, trad., Elena Posa, 1973, pág. 142.

2 TAYLOR, J. Peter, Geografía política. Economía Mundo, Estadonación y Localidad, Madrid, Trama Editorial, trad., Adela Despujol y Cairo Carou, 1994, pág. 63.
}

Otro problema que se plantea estriba en que hablar sobre el Estado conlleva a significarlo desde como él mismo quiere que se lo estudie (la trampa del Estado), comente, o teorice soslayando la crítica a su funcionabilidad. Por ejemplo, bajo el ropaje formalista del derecho a la manera de las teorías puras del Estado que las determine, es decir, las múltiples teorías puras e impuras sobre el Estado que se cumplen como créditos en las academias jurídicas y políticas del campus universitario no pueden concebir el Estado como una génesis dialéctica, una historia critica y unos avances y retrocesos como máquina de máquinas y summa de la teología política que habla Carl Schmitt.

En palabras de Bourdieu (1993), no se pueden dar algunas oportunidades de pensar verdaderamente un Estado que se piensa aún a través de aquellos que se esfuerzan en pensarlo, más que a condición de proceder a una suerte de duda radical dirigida a cuestionar todos los presupuestos que están inscritos en la realidad que se trata de pensar y en el pensamiento mismo del analista.

Esta duda radical parte de considerar el macroespacio (Estado nación) como un bien mueble o inmueble de fácil adquisición y posibles hipotecas en un mercado financiero globalizado, donde se supone que todos ganan porque están asegurados por un campo jurídico neutro y un campo periodístico que denunciaría cualquier estafa.

Por las seguridades aparentes que dan estos dos campos, el país o la nación entran como un bien a una economía de sistemas simbólicos que, estructurada en el desinterés, hace que el macroespacio quede protegido por la máxima aseguradora del conocimiento: el campo científico. El cual, siendo esta una de sus funciones, expide certificados de una "certeza legalizada" en 
forma de protocolos, certificados, códigos y estándares universales que retoma y fortalece la concepción geopolítica clásica velando, de esta manera, las luchas que se dan entre los agentes de los diferentes campos que lo conforman. Es bueno recordar que la geopolítica clásica era una seudo ciencia natural, formalista e idealista que sólo buscaba espacios vitales vecinos o "extraterrestres" como bienestar de una demografía que estaba contra las leyes de Malthus.

Entonces el macroespacio, antes que generar unos conocimientos críticos, ha fundamentado una ideología con discursos múltiples sobre un Estado sin origen ni puntos de ruptura, casi como un dios griego que hubiese nacido de la espuma del mar y que niega la soberanía al convertirla en resultado de una ficción jurídica como lo plantea Badie.

\section{Gubernamentalidad y arte de gobernar el espacio exterior}

La obra De Principatibus (1513) o El Príncipe (1532) a partir de la primera edición póstuma, fija una de las primeras balizas del espacio como exterioridad, en las primeras líneas del famoso libro de Maquiavelo donde puede leerse: "Todas las formas de gobierno y todos los territorios en los que han sido dominados los hombres" ${ }^{\prime \prime}$, es el territorio que todo príncipe, desde el Renacimiento, debe conquistar, adquirir y sostener por todos los medios sin implicaciones morales ni jurídicas.

Pero como sostiene Foucault: "Mantenemos entre paréntesis el problema de sí la interpretación que se ha hecho de Maquiavelo en este debate era o no correcta. Lo esencial es que se intentaba hacer aparecer un tipo de racionalidad que sería intrínseca al arte de gobierno sin ${ }^{3}$ MAQUIAVELO, Nicolás, El Príncipe, Madrid, Editorial Sarpe, trad., Ángeles Cardona, 1983, pág. 29. estar subordinada a la problemática del príncipe, y a su relación con el principado del que es señor y patrón”4.

Entonces El Príncipe tiene su mayor importancia porque abre fronteras a otros manuales o artes no del buen Príncipe sino de las artes del gobierno, ahora no al nivel de las técnicas políticas espaciales de un exterior, sino de las cosas y de los hombres, el manejo al interior del principado y de los Estados soberanos europeos que durante el siglo XVI estaban en formación.

La metáfora clásica del gobernalle (del latín, timón) de toda nave, que permite al capitán que "gobierna" la embarcación llevarla a buen puerto, es retomada también por Foucault: "Por tanto las cosas de las que debe ocuparse el gobierno son los hombres, pero en sus relaciones, ligazones, imbricaciones con esas otras cosas que son las riquezas, los recursos, los medios de subsistencias, el territorio, ciertamente con sus fronteras, sus ciudades, su clima, su sequedad, su fertilidad; son los hombres en sus relaciones con los usos, las costumbres, los modos de hacer o de pensar, etc., y finalmente, los hombres en sus relaciones con esas otras cosas como los incidentes o desgracias [...] pienso que se encontraría fácilmente su confirmación en la metáfora inevitable a la que se refieren siempre estos tratados, es decir, la metáfora del navío. ¿Qué significa gobernar una nave?"5. La respuesta para Foucault, es saber gobernar las cosas y los hombres: "no siendo la propiedad y el territorio más que unas de sus variables"6.

La lección magistral de Foucault presenta otra ruptura importante, es decir, si por un lado el gobierno conduce a una pluralidad de fines determinados para que

${ }^{4}$ FOUCAULT, Michel, La gubernamentalidad en Espacios de poder, Lección en el Colegio de Francia en enero de 1978, Madrid, Ediciones Endymion, 1991, pág. 11. 
produzca riquezas, por el otro, el concepto de soberanía -envuelta siempre en nubosidades escolásticas- será la ficción instrumental que permita la obediencia a las leyes. Por consiguiente, el gobierno no impondrá leyes, sino que dispondrá las cosas: "es decir, utilizará más bien tácticas que leyes, en último término utilizará las mismas leyes como tácticas"7.

Es en el punto anterior donde señala una ruptura de la modernidad que se había iniciado con Maquiavelo en los fines y los medios empleados por el príncipe de turno: "[...] mientras que el fin de la soberanía le era implícito, y se trataba de sí misma y de sus instrumentos bajo la forma de la ley, el fin del gobierno está en las cosas que dirige, en buscar la perfección, en la intensificación de los procesos que dirige, y en los instrumentos de gobierno que en vez de ser leyes serán tácticas multiformes"8

El arte de gobernar encuentra a finales del siglo XVI y principios del XVII una ligazón simbiótica con el Estado, es decir, siguiendo a Foucault, su razón de ser es "la razón de Estado" en el verdadero sentido de la palabra, no de la política, que en modo positivo, cristaliza: "el Estado se gobierna según reglas racionales que le son propias, que no se deducen ni de las solas leyes naturales o divinas, ni de los solos preceptos de prudencia o de sabiduría; el Estado al igual que la naturaleza tiene su racionalidad propia aunque sea de tipo distinto. Inversamente, el arte de gobierno, en vez de intentar encontrar sus fundamentos en reglas trascendentales en un modelo cosmológico o en una idea filosófica-moral, deberá encontrar los fundamentos de su racionalidad en lo que constituye la realidad específica del Estado"”.

\footnotetext{
${ }^{5}$ Ibíd., pág. 16.

${ }^{6} \mathrm{lbíd}$., pág. 16

${ }^{7}$ bíd., pág. 18.

${ }^{8}$ MAQUIAVELO, Nicolás, ob. cit., pág. 29.
}

Este desarrollo, sin lugar a dudas, está ligado al resurgimiento de instituciones específicas y de un habitus (como procesos mentales) en clave de Bourdieu. En sus primeros momentos de expansión del capitalismo mercantilismo-, el arte de gobierno brillará con luz propia en la aparición del gran problema de la población, que liga a la economía, el territorio y los problemas de familia en una conectividad que parecería estar muy alejada de la ciencia de gobierno, para una historia larga, más allá del Tercer Reich, llegando al GULAG soviético y principios del siglo XXI bajo la nueva tensión de las guerras preventivas sustentadas en la USA Patriot Act del 26 de octubre de 2001.

En consecuencia, las lecciones de Foucault y Bourdieu, que posiblemente no estudió el profesor Taylor le hubiesen permitido no caer en la confusión de un neófito cuando expresó: "Los gobiernos son mecanismos 'a corto plazo' para administrar los objetivos del Estado a largo plazo"10, de modo que todos los Estados son servidos por una continua sucesión de gobiernos, olvidando o tal vez desconociendo que es el Estado quien utiliza los sistemas diversos de gobierno para permitir acondicionar los campos y amoldar los agentes que acumulan los diferentes capitales que se dan en toda génesis del Estado y que, a su vez, hacen parte de su estructura de funcionamiento.

Entonces el mejor ejemplo de comprender la génesis del Estado lo expone o examina Bourdieu con los engranajes íntimos y secretos del "monstruo más frío de los monstruos", apenas hipérbole de un gran filósofo como Nietzsche.

\footnotetext{
${ }^{9}$ FOUCAULT, Michel,ob. cit., pág. 19

${ }^{10}$ TAYLOR, J. Peter, ob. cit., pág. 164.
} 


\section{Espacios sociales, campos y capitales en la nueva Génesis del Estado Moderno: Pierre Bourdieu}

Toda analogía sobre el Estado en términos de la biología (vitalismo), la mecánica (determinismo), y la arquitectura (infraestructura o superestructura) son simples analogías que enmascaran una complejidad difusa. El Estado debe ser pensando como un modelo espacial de $\boldsymbol{n}$ dimensiones, superando el modelo topológico de Taylor (1994) para el origen de los Estados territoriales donde sólo existe una pluridimensionalidad de espacios sociales, campos sociales y capitales.

La múltiple dimensionalidad del Estado puede entonces, definirse como una estructura compleja de espacios, campos y capitales que lo fundan, y se solapan en un momento dado, siendo a la vez autónomos conforme a momentos históricos específicos.

El plantear una teoría no lineal sobre el Estado, no encierra ningún prurito antiestatista, es decir, se puede ser crítico desmitificando el Estado, gracias a la inversión total, que puede observarse en los fenómenos centrales de la geografía política: nación, nacionalismos, imperialismos, cartografías irreales e impositivas, etc., desde una perspectiva crítica.

Taylor sostiene, de igual manera Bourdieu: "Las dos instituciones, el Estado y la nación, tienen una relación distintiva con el espacio. Todas las instituciones, de mayor o menor importancia, utilizan el espacio y actúan en el espacio; pero sólo el Estado y la nación están relacionados con un segmento determinado del espacio, un lugar"11.

\section{Ciudadanías}

Para llegar a la concepción de la génesis del Estado, es necesario definir los Espacios sociales, los Campos y los Capitales, conceptos fundamentales en el pensamiento de Bourdieu.

Como sociólogo radical, Bourdieu no acepta simplemente el término sociedad como tal, a lo cual antepone nuevas definiciones como espacio social y Campo, haciendo del primero parte constitutiva del segundo, superando de esta manera los conceptos clásicos de sistema o aparatos.

En principio, los elementos que caracterizan a la propuesta del Campo de Bourdieu, para Morales de Setien serían los siguientes: "1. Son un espacio limitado; 2. Son un espacio de lucha; 3. Son un espacio definido mediante regularidades de conducta y reglas aceptadas; 4. Presentan momentos de crisis coyunturales, donde las reglas que hasta ese momento venían regulando el juego se cuestionan $y$, 5. Son un espacio donde la distribución de fuerzas es desigual"12.

A lo cual agrega, páginas después: "Los campos, sin embargo, se encuentran al interior del espacio social. Bourdieu huye de las connotaciones objetivitas, subjetivistas o nominalistas del término 'sociedad'. En el rechazo de la categoría objetivo/subjetivo que caracteriza a la sociología desde los clásicos y en el intento de superar lo que llama 'la oposición artificial entre las estructuras y las representaciones"13.

\footnotetext{
${ }^{11}$ lbíd., pág. 212.

12 MORALES de SETIEN RAVINA, Carlos, La racionalidad jurídica en crisis: Pierre Bourdieu y Günther Teubner, en La fuerza del derecho, Bogotá, Ediciones Uniandes, Universidad Javeriana, Siglo del Hombre Editores, 2ª reimpresión, 2005, pág. 62.
} 
Para ser específicos, el campo en ningún momento es una estructura artificial e inerte, es un espacio de juego, donde los jugadores creen que apostando el capital que sea, obtienen siempre una ganancia; esta característica de los campos tendrá mayor concreción si definimos, cuáles son los campos que se cruzan, se yuxtaponen, se solapan en todo espacio social o Estado-Nación en formación, es decir, campo económico, político, religioso, lingüístico, jurídico, intelectual y periodístico, que funcionan como abstracciones que requieren estar relacionados con un capital dado, o de lo contrario, quedarían vacíos de lo social: "en otros términos, podría decirse que el objeto central de las luchas y del consenso en cada campo está constituido por una de las diferentes variedades de capital [...] la estructura de un campo es un Estado de la distribución del capital específico que allí está en juego"14.

Por su parte, los Capitales -visibles e invisibles- en un movimiento dialéctico vendrían a ser: capital de fuerza física, capital económico, capital cultural o capital informacional, capital simbólico, capital jurídico y otras formas de capital. Capitales que, analizados per se, permiten en la conceptualidad de Bourdieu "comprender verdaderamente el poder del Estado en lo que tiene de específico, es decir, que la particular forma de eficacia simbólica que ejerce hay que integrarla, en un mismo modelo explicativo, tradiciones intelectuales tradicionalmente percibidas como incompatibles. Hay, así, que superar desde el comienzo la oposición entre una posición fisicalista del mundo social que concibe las relaciones sociales como relaciones de fuerza física y una visión 'cibernética' o semiológica que hace de esas relaciones de fuerza simbólica, relaciones de comunicación"115.

${ }^{13}$ Ibíd., pág. 65.

${ }^{14}$ GUTIÉRREZ, Alicia, Las prácticas sociales: una introducción a

Pierre Bourdieu, Argentina, Ferreyra Editor, 2005, pág. 34.
El estudio de los capitales y de los campos en la teoría bourdesiana, aunque limitados por la extensión de este ensayo, permitirán concretar por ejemplo, algunos argumentos clásicos en la geografía del poder según Agnew (2005) y, aún, en casos específicos de la geografía política, vemos que estos supuestos teóricos, se complementan con la génesis de Bourdieu o los enmarca en una realidad histórica-crítica, que a veces, a causa de su desconocimiento convierte la geografía política en acrítica y sólo como función de ideologías políticas maniqueas, mágicas y míticas.

Así, Agnew señala varias hipótesis que fundamentan la concepción del poder Estado-céntrica: "1. Los Estados tienen un poder exclusivo dentro de territorios, identificado con el concepto de soberanía; 2. Los asuntos 'nacionales' y los asuntos 'exteriores' son realidades esencialmente separadas por normas diferentes; y 3. Los límites del Estado definen los límites de la sociedad de manera que esta última está "contenida' en el primero"16.

Aunque el proceso de concentración de capitales de diferentes especies, en el Estado son interdependientes, en una estructura (de contradicciones y estrategias), por necesidad expositiva se requiere examinarlos individualmente, es decir:

\section{Capital de fuerza física}

Es la concentración del capital de fuerza física, el que ha sido más privilegiado en la totalidad de las teorías que explican el origen del Estado, desde Engels hasta

${ }^{15}$ BOURDIEU, Pierre, "Espíritus de Estado. Génesis y estructura del campo burocrático", en: Revista Sociedad, de la Facultad de Ciencias Sociales(UBA), 1993, pág. 37.

${ }^{16}$ AGNEW, John, Geopolítica: Una revisión de la política mundial, Madrid, Trama Editorial, trad., Maria D. Lois, 2005, pág. 57. 
Althusser, encontramos una concepción de ver el Estado como un formidable aparato de dominación, y coerción. Pero desde Max Weber, observa Bourdieu, "el Estado es una comunidad humana que reivindica con éxito el monopolio del uso legítimo de la violencia en un territorio determinado"16. Pero todas estas implicaciones de fuerza olvidan que "el Estado no ha podido asegurarse progresivamente el monopolio de la violencia sin desposeer a sus rivales interiores de los instrumentos de la violencia física, y del derecho de ejercerla, contribuyendo así a determinar una de las dimensiones esenciales del proceso de 'civilización'"18.

Se desprende entonces que el Estado en formación debe luchar en dos frentes, el exterior, en relación con otros espacios rivales para conservar la tierra; y el interior, contra las fuerzas del príncipe o clases dominantes. Este doble frente tuvo que dividir las fuerzas militares del exterior con un enfrentamiento interestatal, y al interior con unas fuerzas de policía dedicadas al orden. Esta fractura histórica derrumba todo el monopolio de una sola fuerza de coerción concentrada, como si hubiese nacido de la nada o del vientre inmaculado de la violencia más pura.

La violencia brutal y su posterior concentración en las máquinas imperiales y territoriales, en términos de Deleuze y Guattari (1974) es una de las características que permiten acumular estas formas de capital físico con capitales simbólicos, los cuales abordaremos más adelante.

${ }^{17}$ BOURDIEU, Pierre, ob. cit., pág. 21.

${ }^{18}$ Ibíd., pág. 24.

\section{Capital económico}

La concentración del capital de fuerza física, da por resultado la creación de un sistema fiscal, o rentista, conectado a la unificación de un mercado nacional bien delimitado en donde los impuestos habían sido la columna vertebral del Estado dinástico para sostener los gastos de guerra, pero su abusiva obligatoriedad habían ocasionado un conflicto interminable. Esta lógica económica era ya inamovible, más cuando se hace visible que la existencia de las fuerzas armadas, son indispensables "[...] para extender o defender el territorio controlado y, por consiguiente la recaudación posible de tributos e impuestos, pero también para imponer por la violencia la entrega del dinero de ese impuesto. La institucionalización del impuesto ha sido la culminación de una verdadera guerra interior llevada a cabo por los agentes del Estado contra las resistencias de los súbditos[... $]^{\prime \prime 19}$.

El capital económico tiene en el siglo XVI sus inicios junto a una mayor circulación de mercancías y dinero, símbolo de la economía precapitalista, que en algún momento de la historia económica se designa como la "Tríada cataléctica: comercio, dinero y mercados" 20 que desde Aristóteles hasta Marx, eran instituciones consideradas diferentes pero "familiares" [catalécticos] a todo proceso de crecimiento económico. Pero, como bien lo demostró Polanyi, "[...] algunas formas de comercio y varios de los usos de dinero adquieren importancia en la vida económica previa e independientemente de los mercados", por consiguiente, toda historia del capital económico se debe realizar estudiando por separado "[...] el origen del comercio, los usos del

${ }^{19}$ Ibíd., pág. 25.

${ }^{20}$ POLANYI, Karl, El sustento del hombre, Barcelona, Biblioteca Mondadori, 1994, pág. 155. 
dinero y los elementos del mercado"21, evitando el dogma económico, como ciencia totalizadora que permite conceptualizar la sociedad centrada en un desaforado economicismo.

\section{Capital simbólico}

Nunca se repetirá lo suficiente, la lucha teórica que emprendió Bourdieu contra el enfrentamiento entre subjetivismo y objetivismo como lo advierte Téllez: "división artificial y ruinosa", quien sumió la ciencia social en campos de batallas antagónicas: idealismo o materialismo. Bourdieu logra superar las falsas dicotomías, dualidades o polaridades, "[... ] heredadas, sobre todo, de la filosofía de la historia, es decir, de dicotomías como: sociedad / individuo, realidad materia / realidad espiritual, sociología / psicología, cuerpo / alma, estructuras macrosociológicas / estructuras microsociológicas, teoricismo / empirismo, estática / dinámica social, racionalismo / irracionalismo, determinismo y necesidad social" ${ }^{22}$.

Por eso, al abordar la génesis del Estado, Bourdieu, rompe con el economicismo que determinaba al Estado sólo desde la función de acumulación sistemática de capital económico (Marx), olvidando que este capital es uno de tantos capitales que interactúan como estrategias en un momento dado y que dan forma a su Teoría general de la economía de los bienes simbólicos, que le permitieron a Bourdieu romper con las falsas dicotomías y fijar que existen otras formas de capital más sutiles para establecer una legitimación y una dominación más eficaces.

${ }^{21}$ Ibíd., pág. 157.

22 TELLEZ IRREGUI, Gustavo, Pierre Bourdieu. Conceptos básicos y construcción socioeducativa. Claves para su lectura, Bogotá, Universidad Pedagógica Nacional, 2002, págs. 34 - 35.
Entonces la concentración de la máquina estatal (fuerzas armadas e impuestos) necesita un capital especial, el "capital simbólico" para que toda la extracción de dinero y sometimiento a la fuerza física, se acepten como legítimas. Siendo este aceptamiento una forma especial de servidumbre voluntaria que La Botie en el siglo XVI, y Hume en el siglo XVII, analizaban sin lograr hallar una respuesta válida; respuesta a la cual llegó Bourdieu en el siglo XX al desarrollar sus estudios sobre la violencia simbólica, siendo éste uno de sus grandes hallazgos.

Si el capital económico se concentra perfilando los espacios del Estado-nación, el capital simbólico también se cristaliza en un "[...] capital simbólico de autoridad reconocida que, ignorado por todas las teorías de la génesis del Estado, aparece como la condición o, por los menos, el acompañamiento de todas las demás formas de concentración si es que deben tener cierta duración"23.

El capital simbólico entonces, se refiere a cualquier propiedad o especie de capital físico, económico, cultural, social, que permite ser percibido por los agentes sociales como justo, valioso y que puede ser desde el "honor" y los títulos académicos como no títulos valores, etc., que permiten encausar "la legitimidad de la violencia" no de fuerzas represivas burdas, sino otras formas de "violencia simbólica", intangibles, más gaseosas, de apariencias más neutras como pueden ser por ejemplo, el capital jurídico. Formas que toma el capital simbólico de manera objetivada, codificada y fetichizada, en un ejemplo histórico que trae Bourdieu: "es así como la realeza al apoyarse en los intereses específicos de los juristas (ejemplo típico de interés en lo universal) crean toda clase de teorías legitimadoras

${ }^{23}$ BOURDIEU, Pierre, ob. cit., pág. 30. 
según las cuales el rey representa el interés común, da a todos seguridad y justicia, restringe la competencia de las jurisdicciones feudales [... $]^{\prime 24}$.

Así, la acumulación de capital simbólico permite por ejemplo, la aparición del mundo burocrático, porque fundamenta el reconocimiento de los burócratas como necesarios, con licencia o títulos que los confirman como tales. También se preguntaba Bourdieu por la autoridad que apostilla esos títulos simbólicos: "Pero, ¿quién lo certifica a él a su turno? Esto entraña una regresión al infinito, al término de la cual 'hay que detenerse' y se puede, a la manera de los teólogos, elegir dar el nombre de Estado al último (o al primero) de los eslabones de la larga cadena de los actos oficiales de consagración. Es él que, al oficiar como un banco de capital simbólico, garantiza todos los actos de autoridad, actos a la vez arbitrarios y mal conocidos como tales de 'impostura legítima' como dice Austin: el presidente de la República es alguien que se cree ser el presidente de la República porque, a diferencia del que cree ser Napoleón, es reconocido con fundamento para serlo" 25 .

Estas redes invisibles del Estado, se revelan mejor si consideramos el microcosmos burocrático, como el caldo de cultivo más eficaz de producir "sistemas simbólicos" a la manera de Cassirer y de "clasificación" como dice Durkheim. Principios que, según Bourdieu son vestidos con el traje del sentido común, aceptados como naturales, que ocultado su artificialidad por una cientificidad como la geografía física se deriva en una geopolítica clasificatoria, universalista e intimidante como arma política, que esgrime nociones cual si fueran fronteras interiores o exteriores, espacios vitales

${ }^{24}$ lbíd., pág. 32.

${ }^{25}$ lbíd., pág. 36.
(Lebensraum) y pluriespaciales como el corazón continental (Heartland del siglo XIX) o la forma Imperio, que cubre todo el espacio global originando la dominación planetaria total para el siglo XXl.

Bourdieu ajeno a todo profetismo o futurología a lo Toffler, analizó cómo en sociedades bien diferenciadas "[... el Estado es capaz de imponer y de inculcar de manera universal, a escala de una cierta jurisdicción territorial, un nomos (que proviene de nemo, partir, dividir, constituir partes separadas), un principio de visión y de división común, estructuras cognitivas y evaluativas idénticas o parecidas y que es, por ese hecho, el fundamento de 'un conformismo lógico' y de un 'conformismo moral' acerca del sentido del mundo"26. Resultante grandioso del capital simbólico, acuñando legitimidades simbólicas con sus troqueles invisibles, acuñando igualmente capitales intangibles que circulan marcando al fuego, como al ganado, sus campos respectivos (políticos, jurídicos, intelectuales, etc.) convirtiéndolos de esa manera como naturales e inmanentes.

\section{Capital cultural o informacional}

La definición de Téllez sobre esta especie de capital es clara y precisa: "[...] se puede asociar con la forma específica (sistemas y códigos) que adopta la cultura. A diferencia de otras formas de capital, éste presenta propiedades derivadas de su carácter incorporado, ya que su acumulación implica la interiorización del trabajo pedagógico de inculcación y asimilación de un orden específico a lo largo del tiempo"27.

Esta acumulación y maximización, para el caso del capital cultural o informacional, se ve en la arrogancia

${ }^{26}$ Ibíd., pág. 38. 
de los poderes públicos publicitando, sus proyectos pedagógicos y culturales, en eventos que copan todo el tiempo disponible, que demarcan y cuentan con una puntillosa estadística (ciencia que calculaba el error) y hoy, como su nombre lo indica, desinforma sobre los asuntos del Estado.

Es el capital de objetivación en Bourdieu, "por la cartografía, representación unitaria, a sobrevuelo, del espacio o, simplemente, por la escritura, instrumento de acumulación del conocimiento (con el ejemplo de los archivos) y de la codificación como unificación cognitiva que implica una centralización y una monopolización en provecho de los clérigos o de los letrados" ${ }^{28}$. Apareciendo de esta manera la educación pública, universidades, escuela, etc.

El capital cultural, al unificar el Estado lo homogeniza en todos sus códigos y formas de comunicación, imponiendo la legitimidad nacional desde su sistema escolar propulsor de la imagen Republicana, avalada en historias patrias y políticas publicando manuales de estilo, de urbanismo, comportamiento y buenas palabras. Sistemas o códigos siempre arbitrarios, que Bourdieu señala en contra vía del chauvinismo francés como "[...] la dimensión nacionalista de la cultura se enmascara, en el caso de Francia, bajo apariencias universalistas: la propensión a concebir la anexión a la cultura nacional como promoción a lo universal funda tanto la visión brutalmente integradora de la tradición Republicana (nutrida principalmente del mito fundador de la Revolución universal) como formas muy perversas de imperialismos universalista y de nacionalismo internacionalista" 29 . Y hoy, a nivel

${ }^{27}$ TELLEZ IRREGUI, Gustavo, ob. cit., pág. 75.

${ }^{28}$ BOURDIEU, Pierre, ob. cit., pág. 27. global, la implementación de la democracia en todos los rincones del planeta contra todas las formas de autodeterminación religiosa, moral y política de los pueblos

\section{El Estado derrumbado (collapsed state) y la emergencia del espacio global}

El haber señalado, si se quiere en forma esquemática, la génesis del Estado según Bourdieu, permite tener un marco histórico de referencia, no desde el determinismo vuelto sentido común, sino desde la operatividad y las estrategias de los diferentes capitales y sus espacios sociales, que son al final los vectores que van a permitir el diseño de toda la geopolítica clásica desde su formación hasta nuestros días.

Pero si algo queda del espacio-nación y su corazón, de la soberanía como teoría y entidad geográfica, son las ficciones jurídicas de "razones de Estado" secretas y acomodaticias; más cuando los espacios geográficos se derrumban en su interioridad y exterioridad amenazada por las relaciones internacionales en conflicto permanente y que Brzezinski de forma precursora por lo demás, considera como "[...] la creencia institucionalizada se desarrolla en el contexto de la revolución tecnotrónica, una revolución que no es territorial sino espaciotemporal" ${ }^{\prime \prime 2}$.

Una de estas creencias tiene que ver con el concepto de soberanía sometido a tensiones políticas y jurídicas desde su génesis, que hoy lo tienen como una ficción geopolítica en vía de extinción. Una breve enumeración

\footnotetext{
${ }^{29}$ lbíd., pág. 30

${ }^{30}$ BRZEZINSKI, Zbigniew, La era tecnotronica, [Between Two Ages. America's Role in the Technetronic Era ], Buenos Aires,Editorial
} Paidos, 1970, pág.172. 
de autores permitirá probar esta decadencia si así se quiere, del emblema jurídico representativo de estas ideas políticas.

Tomando a Zbigniew Brzezinski como uno de los primeros teóricos que tiene la visión de un modelo global estratégico del mundo, "La rivalidad entre las naciones está insita en un sistema internacional que funciona sin el consenso global y es el producto de siglos durante los cuales la cosmovisión del hombre estuvo condicionada por naciones rivales que exaltaban su superioridad individual y sus valores particulares. No es probable que esta rivalidad desaparezca, a menos que se practique una reconstrucción fundamental de las relaciones entre las naciones y por tanto, del concepto mismo de soberanía nacional" ${ }^{\prime \prime 31}$.

Con solo mirar al exterior de los espacios domésticos se comprueba la mutación del Estado Soberano. Sirve de paradigma la crisis de Colombia y Ecuador (marzo 2008) ayer y hoy, al momento de escribir este ensayo, Colombia y Nicaragua, tienen en sus componentes no un enfrentamiento racial o de espacios vitales de ampliación fronteriza derivado del consenso planetario de guerra contra el terrorismo, acuerdos que según Brzezinski: "En verdad, en nuestra era internacional los acuerdos de seguridad deben parecerse a los que rigen en los grandes centros urbanos: estos acuerdos no apuntan contra determinados individuos u organizaciones, sino contra quienes se apartan de las normas estipuladas"32. Acuerdo internacional como el actual Derecho de Persecución o hot pursuit, persecución en caliente, que permite a un Estado entrar manu militari a otro, no sólo violando sus fronteras sino su soberanía, quedando del antiguo Derecho Internacional algo menos que el solo nombre.

\footnotetext{
31 lbíd., pág. 424.
}

${ }^{32}$ Ibíd., pág. 432.
La soberanía está representada por el canon clásico Bodin y Hobbes estabilizada más tarde con el triunfo de la Revolución francesa y sus grandes llustrados Rousseau y Montesquieu. Badie la llama una compleja invención que será la verdadera sustancia de la República, porque su existencia depende de sí es soberana y su poder es absoluto e indivisible en un espacio francés desgarrado por luchas de facciones. Aunque muy de su propio contexto localista, la teoría de Bodin penetra un largo periodo de la historia constitucional del Estado europeo: "Está claro que con Bodin, la idea de Estado progresa considerablemente: el príncipe ya no basta para definir la soberanía, su naturaleza humana e individual lo descalifica y lo arrastra a relaciones de vínculo. La soberanía no existe si el poder que lo fundamenta no es perpetuo, si no se basa en una distinción clara entre Estado y gobierno, en la indivisibilidad de la República y en una trascendencia afirmada" ${ }^{33}$.

Badie señala cómo Bodin percibe la grieta del posible derrumbe de la soberanía al decirnos: "El poder absoluto y soberano sólo puede pertenecer a Dios, la ley divina y la ley natural no pueden más que trascender toda soberanía humana"34. Agujero negro de las monarquías soberanas, por donde se hundirán y, al cual la revolución burguesa se encargará de desacralizar -no confundir con desacreditar- la ley humana contractual será entonces la mano laica del nuevo Dios burgués.

Pero la soberanía tenía también una contradicción: el Estado nacional y soberano para existir debía buscar alianzas, ligas, y uniones locales (que en el futuro se convertirían en supranacionales), como forma de cohesión ya no territorial, de supervivencia política,

${ }^{33}$ BADIE, Bertrand, Un mundo sin soberanía. Estados entre artificio y responsabilidad, Bogotá, Universidad Externado de Colombia, Tercer Mundo Editores, 2000, pág. 7.

${ }^{34}$ Ibíd., pág. 8. 
espacio internacional, contradicción hoy resuelta en la globalización como esencia del capitalismo liberal.

Si la soberanía hoy es relativa en una sociedad global, las fronteras flexibles, entonces iqué nos queda del Estado? Para responder a esta compleja pregunta seguimos a Badie (2000) cuyos ejemplos actuales constituirían paradigmas innumerables desde el Cuerno de África a la antigua Yugoeslavia, de ésta a Afganistán, Irak, Haití o Colombia, etc. Encontramos entonces que las estructuras de autoridad y soberanía han implosionado puesto que, "[... ] desde que un Estado se derrumba hasta el punto de no ser más soberano, es aceptable si no legítimo que la comunidad internacional intervenga en sus propios asuntos, incluso que sustituya a una autoridad que se ha vuelto deficiente e incluso decadente, con el fin de restablecer el orden" y "Colombia se uniría entonces al club de los collapse status como cualquier sociedad en la que el terrorismo sobrepasa un umbral crítico, por supuesto imposible de definir objetivamente" ${ }^{\prime 35}$.

Estas afirmaciones certificarían al "Estado derrumbado", pero que según el mismo Badie es una hipótesis floja, arbitraria y subjetiva que sólo se concretará si este desmoronamiento es avalado por una certificación de la comunidad internacional, así de alguna forma empieza a definirse a los Estados como "Leviatanes cojos" o "Leviatanes derrotados"36 en la teoría de Víctor Manuel Moncayo. De esta manera se explica cómo el campo periodístico se pone al servicio o intercepta al campo político al declarar que un país como Venezuela, por ejemplo, puede entrar a colapsar no por ser terrorista sino por ayudar y reconocer a grupos terroristas, circunstancia que lo llevaría a ser incluido como otro de los países del eje del mal junto a Irán, Corea y otros.

35 Ibíd., pág. 84

${ }^{36}$ T. Callaghy, en: BADIE, Ibíd., pág. 84.
Explicar esta ruptura nos lleva a pensar en la existencia de un cataclismo político sustentado en una nueva revolución conservadora en la sociedad, la cual está hoy bien demarcado en las teorías fuertes de la sociedad post-industrial de Daniel Bell (1976) - la revolución tecnotrónica (Technetronic Era) de Zbigniew Brzezinski (1970), en donde el Estado soberano había empezado a mutar en una nueva especie monstruosa: la famosa global governance. $Y$ eso es lo que tenemos hoy.

Estas revoluciones neocons, quedan inscritas en el hegemón, término griego que esconde una realidad concreta, que sólo la podemos visualizar, si leemos al principal estratega Estadounidense, que, de forma precisa y elegante concluye en una de sus obras esenciales: "En pocas palabras, la meta política de los Estados Unidos debe ser necesariamente doble: la de perpetuar la propia posición dominante de los Estados Unidos durante al menos una generación -y, preferiblemente durante más tiempo aún- y la de crear un marco geopolítico capaz de absorber los choques y las presiones inherentes al cambio sociopolítico avanzando al mismo tiempo en la construcción de un núcleo geopolítico de responsabilidad compartida de la gestión pacifica del planeta"37.

El espacio se ha vuelto unidimensional, hegemónico, y el militarismo unilateral, viejo sueño de los geopolíticos clásicos que hoy ha reencarnado se ha vuelto realidad planetaria en las guerras puntuales y secretas orquestadas contra los gobiernos que no representan sus intereses. Tomaríamos como ejemplos el caso de los movimientos "autonomistas" Bolivianos; el corte

${ }^{37}$ BRZEZINSKI, Zbigniew, El gran tablero mundial. La supremacía Estadounidense y sus imperativos geoestratégico, Barcelona, Editorial Paidos, pág. 217. 
de rutas de los propietarios del agro contra el Estado Argentino, el desabastecimiento de alimentos en Venezuela entre muchos otros casos y próximamente en Ecuador y Nicaragua.

Así los agentes geopolíticos, quienes han sido reconocidos como legítimos e invisibles, están utilizando, a su manera, las formas de violencia simbólica que son sustento del poder simbólico, siendo "el poder simbólico un efecto, de ese poder invisible que no puede ejercerse sino con la complicidad de los que no quieren saber que lo sufren o incluso que lo ejercen" ${ }^{\prime \prime 3}$ Bourdieu. Al respecto, Manuel Fernández sostiene que la violencia simbólica está ligada a la dominación científica cuando Bourdieu dice: "La oposición entre la infraestructura y la superestructura o entre lo económico y lo simbólico no es, según él, nada más que la más amplia de una serie de oposiciones ficticias, como presión o sumisión voluntaria, manipulación centralista o automistificación espontaneísta, que impiden comprender adecuadamente la lógica infinitamente sutil de la violencia simbólica que se instaura en la relación, opaca para símisma, entre los cuerpos socializados y los juegos sociales en los que están implicados"39.

Este poder simbólico de "sistemas simbólicos" propios e instrumentos de conocimiento y de comunicación, de construcción de la realidad, orden y sentido del mundo homogéneo, que se da en un sentido lógico y conforme al tiempo y al espacio, punto de un discurso oficial, que como veremos en el apartado siguiente, es también el discurso del geógrafo, político, diplomático, etc., que conforman la teoría de la geopolítica crítica de hoy, que tiene en Agnew, su más calificado representante.

${ }^{38}$ BOURDIEU, Pierre, Sobre el poder simbólico, en Intelectuales, política y poder, Buenos Aires, Editorial Universitaria de Buenos Aires, Trad. Alicia Gutiérrez, 5ª reimpresión, 2006, pág. 66.

\section{La geopolítica crítica y la "deconstrucción" de John Agnew}

Agnew define a los Intellectually of Statecraft, "como el staf de intelectuales que tiene a su servicio el Estado" 40 junto con los medios periodísticos de forma sibilina, think thanks mientras Bourdieu los define como los diseñadores de un imperialismo de la razón liberal, realzado por dos nuevas figuras de productores culturales: "Primero, en el experto, quien prepara, en la oscuridad de los pasillos ministeriales o con complicidad de los think thanks, documentos de alta calidad técnica, traducidos lo mejor posible a un lenguaje económico y matemático. Luego el consejero de comunicación del príncipe, tránsfuga del mundo universitario al servicio de los dominantes, cuya misión es poner en términos académicos los proyectos de la nueva nobleza del Estado y de la empresa" 41 , lo cual nos permite entender cómo funciona ese mecanismo al hacer una relación de políticos y especialistas, que aportaron sus capitales simbólicos respectivos y que llegan a nuestros días como estrategas del mundo globalizado, que hoy rigen todas las relaciones internacionales. La tabla siguiente nos ilustra sobre los agentes que lo componen.

Es claro que esta discreta "captación" y "cooptación" de profesionales por el Estado y para el Estado, permanece en la penumbra encubierta por ficciones jurídicas o políticas, que el sentido común acepta per se, ejemplos vivos de una especie de magia y misterio, que necesita ser revelado,

${ }^{39}$ FERNÁNDEZ, J. Manuel, "La noción de violencia simbólica en la obra de Pierre Bourdieu: una aproximación crítica”, en: Cuadernos de trabajo social, Universidad Complutense de Madrid, Vol. 18, Madrid, 2005, pág. 20.

${ }^{40}$ AGNEW, John, ob. cit., pág.11.

${ }^{41}$ BORDIEU, Pierre, "La nueva Vulgata planetaria", en: Revista Colombiana de Educación, Número especial en memoria de Pierre Bourdieu, Bogotá, U. Pedagógica Nacional, No. 42, 2002, pág. 11. 


\begin{tabular}{|c|c|c|c|c|}
\hline \multicolumn{5}{|c|}{ TABLA No. 1 CUADRO DE HONOR DE LA GEOPOLÍTICA } \\
\hline AUTOR & PAÍS & CRONOLOGÍA & PROFESIÓN & TEORIA \\
\hline MONROE. & E.U. & $1816-1825$ & Presidente & "Destino manifiesto" \\
\hline ROOSEVELT. T. & E.U. & $1858-1919$ & Presidente & "I took Panamá" \\
\hline LENIN & URSS & $1870-1924$ & Político & El imperialismo fase superior ... \\
\hline EISENHOWER & E.U. & $1890-$ & Militar, Presidente & "Efecto dominó" \\
\hline RITTER & Alemania & $1779-1859$ & Geógrafo & \\
\hline KJELLEN & Suecia & $1864-1922$ & Geógrafo, político & Inventa término "geopolítica" \\
\hline HITLER & Alemania & $1889-1945$ & Canciller & "El Estado racista" \\
\hline CHURCHIL & Inglaterra & $1874-$ & Político & "La cortina de hierro" \\
\hline MACKINDER & Inglaterra & $?$ & Político & Corazón continental \\
\hline RATZEL, F & Alemania & $1844-1904$ & Geógrafo & Estado como organismo \\
\hline HAUSHOFER & Alemania & $?$ & Militar geógrafo & Espacio vital \\
\hline MAHAN, A. & E.U. & $1840-1914$ & Militar & Dominio naval \\
\hline KENNAN, G & E.U. & $?$ & Diplomático & Contención \\
\hline LIPPMAN, W & E.U. & $?$ & Diplomático & Concepto Guerra Fría \\
\hline GORBACHEV & URSS & * & Político & "Glasnots" \\
\hline KISSINGER & E.U. & * & Académico, político & $\begin{array}{l}\text { Geopolítica de la Guerra } \\
\text { Fría }\end{array}$ \\
\hline BELL & E.U. & * & Académico, asesor & Sociedad Postindustrial \\
\hline BRZEZINSKY & E.U. & * & Académico, asesor & Geoestrategia Global \\
\hline HUNTINGTON & E.U. & * & Académico, asesor & Choque de civilizaciones \\
\hline AGNEW & E.U. & * & Académico & $\begin{array}{l}\text { "Imaginación política } \\
\text { moderna" }\end{array}$ \\
\hline O TUATHAIL & E.U. & * & Académico & "Critical Geopolotics" \\
\hline TAYLOR & Inglaterra & * & Académico & $\begin{array}{l}\text { Sistemas mundiales } \\
\text { (Wallerstein) }\end{array}$ \\
\hline
\end{tabular}

"Autores vivos 
pero que escapa a los propósitos de este ensayo.

Toda esta larga digresión se hace necesaria para aproximarnos al trabajo de John Agnew y su discípulo Gearoid O., Tuathail al estudiar su deconstrucción de la geopolítica clásica y la aparición de otra geopolítica más crítica.

No es nada casual que la tesis doctoral de Gearoid O. Tuathail, dirigida por Agnew en 1989, lleve como título: Critical geopolitics: The Social Constructions of Space and Place in the Practice of Statecraft, tesis no publicada, pero siguiendo a Cairo Carou nos permitió ver la geopolítica clásica fundamentada en un Estado centrista, que bajo la forma de sus discursos políticos, se hacían pasar como formas

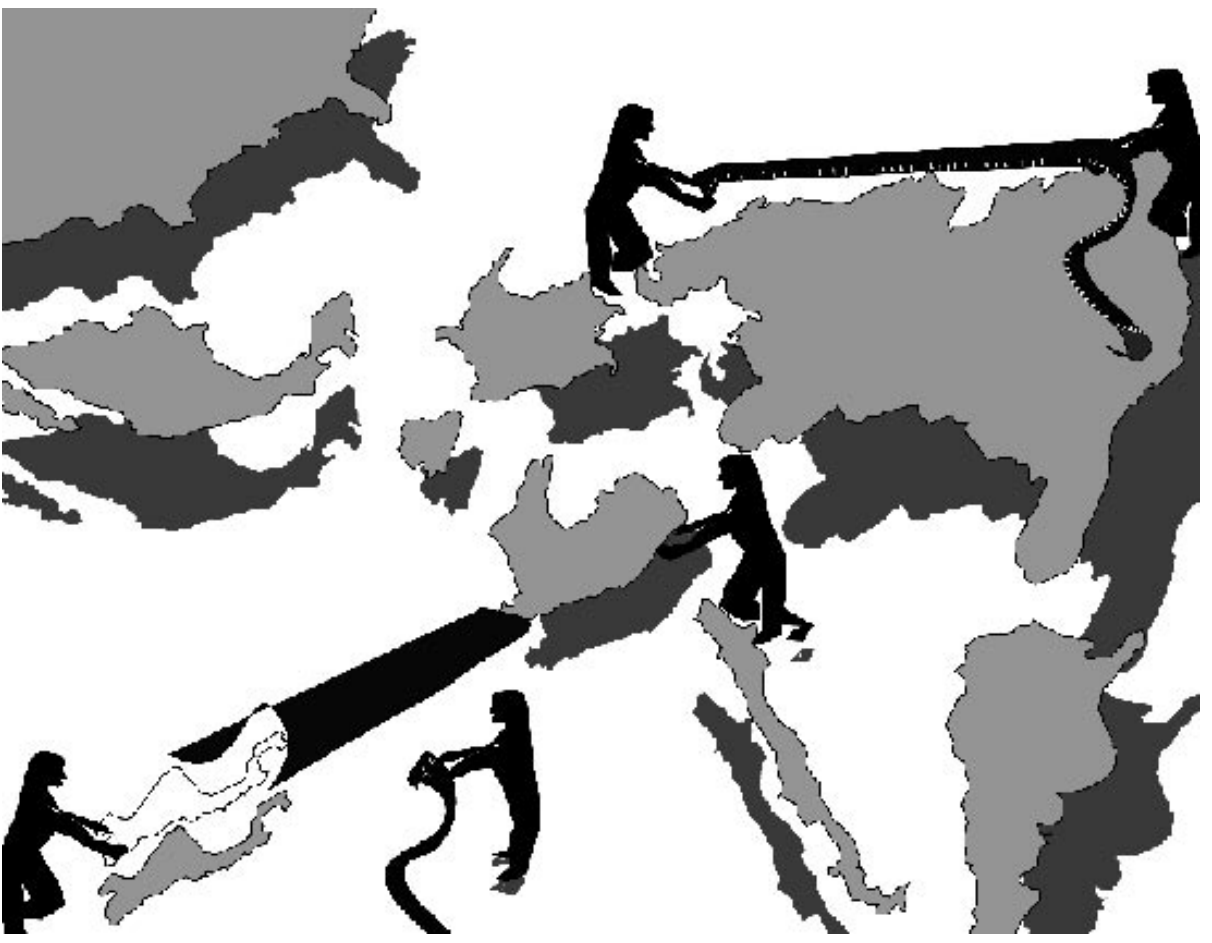
naturales, y como la pantalla de una geografía física, convertidos en universales:

"Las características geográficas que constreñían o determinaban las actividades de los Estados eran contempladas como realidades fijas o, al menos estables. La disposición de las tierras y los océanos o los ciclos económicos ofrecían una regularidad a la explicación geopolítica"42.

Esta articulación al ver la geopolítica como un campo intelectual, estructurado, que se hipostasiaba en el Estado / poder, gracias a los determinantes de una teoría económica marxista o en el otro extremo al tormentoso final de la "infamante geopolítica alemana"

como definió Taylor, al retomar como referente los elementos teóricos de la economía-mundo de Wallerstein, estructuraba una teoría que en su momento (1979), podía funcionar, pero que de ninguna forma llegaría a ser la estructura básica de una explicación geopolítica válida donde el discurso económico se hacía funcionar como centro del mundo.

En contraste con este economicismo, la crítica de Agnew se centra en desenmascarar los presupuestos equívocos de la geopolítica clásica que, como se sabe, había quedado destruida por la Segunda Guerra Mundial en 1945. Su tesis central se fundamenta en

${ }^{42}$ CAIRO, Carou, en: AGNEW, ob. cit., pág 15. 
considerar las estructuras sin centro alguno y por tanto el poder estará siempre descentrado en micro-poderes, que cruzan al sujeto y al saber; no lo determinan puesto que son construcciones complejas y difusas, que marcan el cuerpo, por las disciplinas del espíritu y del cuerpo (confesión/castigo).

Así hoy nos encontramos frente a un poder, positivo en cuanto éste no prohíbe, sino también porque produce saberes específicos, es decir, una historia sobre el cuerpo (ya sea el que produce la prisión o la universidad), como universales y casi naturales (Biopoder) y, lo que es más importante, sin validez ni pretensiones metafísicas sobre un sujeto único e inmutable.

Volviendo de nuevo a Foucault, el hombre como concepto ha muerto, sólo existe el sujeto: vuelto maquina (Deleuze), disciplinado, sometido con alegría a las extraordinarias mutaciones culturales y corporales.

Los saberes son asistémicos y descentrados en todo el espacio social, porque ahora son rediculares y con nodos múltiples, ahora el discurso conforma y formatea al sujeto puesto que éste parece disponer de una libertad absoluta, pero siempre hace lo que su programa le indica -en la legitimidad del poder-, disfrutando de bienes superfluos a manos llenas, en un mundo donde la mercancía y el mercado son los determinantes del espacio global, flexible y deslocalizado en sus máscaras de poder y discurso, existiendo en un presente eterno, tiempo único de un planeta, ya sin historia.

Los post-estructuralistas son señalados de nihilistas, relativistas y de un marcado tinte amargo en su teoría pero, como veremos a continuación, la teoría deconstructiva de Agnew es productiva por la compleja reflexión crítica que presenta, esfuerzo enfocado a deslegitimar a la geopolítica clásica solo como simple relato imaginativo, no cínico, ni menos un "nihilismo autocomplaciente", como afirman sus detractores, por el contrario su proyecto es estudiar la geografía política de una forma alternativa, cuestionando los supuestos en los que se fundamentan sus discursos y sus imágenes, propios de un conocimiento más espontáneo que científico.

Deconstrucción y reconstrucción, para Agnew son dos procesos que se alimentan mutuamente, como nos enseña Gómez Sánchez, "para hacer de la geopolítica una práctica liberadora basta con construirla en oposición a los presupuestos que hacen de ella un arma de dominación. Ni más ni menos"43.

De forma por demás simple, los análisis de Agnew deconstruyen el mito de una objetividad total de toda la geopolítica, o sea, la ilusión antropocéntrica de que podamos ser a la vez objetos empíricos de conocimiento y sujetos trascendentales de un conocimiento supremo, rompiendo así con la polaridad sujeto / objeto y buscando en palabras de los post-estructuralistas, una actitud epistemológica más reflexiva.

Valga un ejemplo, citado por Cairo de una obra reciente del profesor Agnew, American Space/American place: Geographies of the Contemporary United States, donde señala una diferencia esencial, muchas veces olvidada por los geógrafos de academia y confundida, en discursos políticos que, compás y escuadra en mano, trazan utópicas cartografías constitucionales:

${ }^{43}$ GÓMEZ, Lucía, Procesos de subjetivación y movimiento feminista. Una aproximación política al análisis de la identidad contemporánea, España, Universidad de Valencia, Tesis doctoral, 2003, pág. 209. 
Espacio [space] es una "imagen convencional", construida a partir de una tradición Estadounidense $(0$ de cualquier país), promulgada y hecha relato, con la racionalidad que puede dar una historia oficial. Campo de acción o área en la que un grupo o Estado determinado fija en cartas geográficas lo que es y aspira a ser.

Lugar [place] que representa el encuentro de la gente con otra gente y con las cosas del espacio, relación cotidiana y dinámica en continuo cambio y desarrollo: "No sólo con relación a ese relato nacional, sino también como resultado de influencias locales y globales" 44 .

\begin{tabular}{|c|c|c|}
\hline \multicolumn{3}{|c|}{ TABLA No. 2: LAS TRES ERAS DE LA GEOPOLÍtICA SEGÚN JOHN AGNEW } \\
\hline Cronología & ERAS & Características \\
\hline $1815-1875$ & $\begin{array}{c}\text { Geopolítica civilizatoria } \\
\text { (Civilizational) }\end{array}$ & Europa centro del la cultura \\
\hline $1875-1945$ & $\begin{array}{c}\text { Geopolítica naturalizada } \\
\text { (naturalized) }\end{array}$ & El Estado naturalizado \\
\hline $1945-1990$ & $\begin{array}{c}\text { Geopolítica ideológica } \\
\text { (ideological) }\end{array}$ & EEUU-URSS(lucha ideológica) \\
\hline
\end{tabular}

Fuente: Agnew $^{46}$
Agnew, desde su introducción insiste en que la geopolítica es el resultado de una imaginación política que se inicia en el siglo XVl: "Hace mucho tiempo que esta imaginación geopolítica estructura la política mundial a modo de un contexto global, la imaginación geopolítica es especialmente moderna. El mundo es activamente 'espacializado', dividido, etiquetado, clasificado por geógrafos políticos, otros académicos y líderes políticos en una clasificación de lugares de mayor o menor 'importancia'"45.

A lo cual sumariamos que son los "Estados canallas" del presidente G.W. Bush o sus antecesores, los mal llamados países que configuran los "ejes del mal" y sus razas débiles que infestaban a toda Europa, o mucho antes de toda historia. Bárbaros sin lugar ni espacio, etiquetas que todavía se perfilan como discurso político de dominación y legitimación oficial, bajo la forma de geopolítica racional, hoy eufemizada en relaciones internacionales.

${ }^{44}$ CAIRO, Carou, en AGNEW, ob. cit., pág. 14.

${ }^{45}$ AGNEW, John, ob. cit., págs. 1 - 3.
Por otra parte, Agnew define diferentes eras de la geopolítica como se puede ver en el cuadro siguiente:
Puede verse en la Tabla anterior, elaborada a partir de lo que parecen ser las conclusiones más determinativas de Agnew, el movimiento sostenido de tres discursos representativos de una imaginación política que marca largos periodos de la historia, presentando continuidades de temas siempre idénticos, pero bajo nuevas variaciones. No será de forma imprudente pensar que la imaginación geopolítica sólo ha sostenido - a modo de pantalla- una sola cosa: renovadas formas de intervención de una potencia sobre otros espacios vecinos o lejanos, bajo las ideologías de la civilización, la cultura, la democracia y otros eufemismos, que cubren la forma económica de una explotación por otras mercancías de valor en los mercados imperialistas de ayer y globales de hoy.

Este asunto de las eras geopolíticas es reflejo de un cientificismo el cual pretende decirnos que no hay más formas posibles de clasificación, que la historia es inmutable, un círculo vicioso y al cual se adhieren los representantes de la academia sin siquiera cuestionarlas.

${ }^{46}$ Ibíd., págs. 101-135. 


\section{El espacio geográfico como búsqueda del poder simbólico (un caso práctico: el fallido proyecto de reforma constitucional de la República Bolivariana de Venezuela)}

"En el origen de la ley no hay más que arbitrariedad y usurpación, de que es imposible fundamentar el derecho en la razón y el derecho, y de que la constitución, lo que más se parece, sin duda, en el orden político, a un primer fundamento cartesiano, no es más que una ficción fundadora pensada para ocultar el acto de violencia fuera de la ley que constituye el principio de la instauración de la ley".

Bourdieu ${ }^{47}$

Bourdieu nos ubica en el discurso que sostiene todo formalismo constitucional, "para que se comprenda hasta qué punto los lingüistas no hacen más que incorporar a la teoría un objeto pre-constituido cuyas leyes sociales de construcción olvidan y cuya génesis social en todo caso enmascaran, no hay mejor ejemplo que los párrafos del Curso de lingüística general en donde Saussure, discute las relaciones entre la lengua y el espacio. Queriendo probar que no es el espacio lo que define la lengua, sino la lengua lo que define su espacio"48. Equivocación que oculta la historia políica de la construcción social del espacio, como discurso institucional (Constitución Política) que parte de una codificación, y una imposición generalizada.

Todo modelo constitucional conjuga los diferentes sentidos de instituere y de institutio, en la entidad única (Constitución) que tiene únicamente la función de INSTITUIR. En otro sentido, inaugurar, fundar un país, un Estado determinado por unas fronteras espaciales únicas y univocas. En contravía de Saussure, es el

${ }^{47}$ BORDIEU, Pierre, Meditaciones pascalianas, Barcelona, Editorial Anagrama, 1999, pág. 221.

${ }^{48}$ BORDIEU, Pierre, ¿Qué significa hablar? Economía de los

intercambios lingüísticos, Madrid, Akal, 1985, pág. 18. espacio que funda, no sólo en el ámbito de la lengua que se habla en él, sino también en la geografía física que lo determina, en sus conquistas, sus disputas fronterizas, o sus proyectos utópicos como lo tratamos anteriormente, es decir, de querer abarcar, desde un espacio limitado, todo el mapa del mundo.

Así, toda Constitución que, a partir de un acto inaugural, se constituye como codificación de normas que se pretenden eternas (patria, religión, raza, etc.) también consagra e instituye un ESPACIO (tierra, agua y aire) que al final es la geografía física del macroespacio, soporte del nuevo Estado. Podría asegurarse entonces que la geografía política vendría a ser el Código Civil, en lo que tiene que ver como persona jurídica (Yo soy el Estado), sus bienes (espacios físicos), sus contratos ("geometría del poder") y las herencias ("células geohumanas") que deja a las "nuevas generaciones" el aire puro, riquezas hídricas y otros bienes siempre en peligro de agotamiento.

Pero la Constitución política o Carta Magna (carta de navegación en fina retórica política), es decir, el espacio, tiene una fuerza de representación casi mágica a lo cual Bourdieu observa que la confusión de los debates sobre la noción de región y, más generalmente de "etnia" o de "etnicidad" (eufemismos cultos que sustituyen la noción de "raza", aunque esta noción esté siempre presente en la práctica) se deben al afán de someter a la crítica lógica las categorías del sentido común, prenociones muy alejadas de toda ciencia.

Como es bien sabido, el sentido común siempre ha sido mal consejero en la historia social, está permeado por manipulaciones simbólicas o representaciones mentales donde los criterios objetivos quedan enmascarados por luchas y estrategias de grupo o de naciones. En efecto, retomando a Bourdieu, lo que se ventila en esas luchas 
es la posibilidad de imponer una visión del mundo social a través de principios de división que, cuando se imponen al conjunto de un grupo, constituyen el sentido y el consenso sobre el sentido y, en particular, sobre la identidad y unidad que hace efectivas la realidad de la unidad e identidad de ese grupo.

Vemos el ejemplo del Proyecto de reforma constitucional de Venezuela, que no sólo fracasa en un plebiscito, sino que acaba tensionando un enfrentamiento clasista de toda la sociedad dejándola a los vaivenes del Juan Vicente Gómez de turno.

Lo que se introduce por decreto, acto demiúrgico de toda Constitución en sí, es la paradoja de hacer una discontinuidad fundamental en la propia continuidad natural, sea de las regiones o del espacio troceado en finos elementos. Bien lo sabían los griegos, que al hablar de la línea recta ésta sólo era una sucesión de puntos, al clasificar el espacio, los constituyentes Venezolanos se quedaron con los puntos de otra cartografía semejante a la del famoso cuento de Borges.

Se olvida muy a menudo que el mapeo de líneas fronterizas que separan el interior y el exterior del territorio nacional y el extranjero es un acto religioso que se encomienda a los ancianos de la polis, o al rey, quienes hablan con autoridad, escribiendo los textos transmutados, en letras sagradas que con el paso del tiempo crean, predicen y promulgan el futuro. "La región (regio) y sus fronteras (fines) no son otra cosa que la huella muerta del acto de autoridad consistente en circunscribir el país, el territorio (que se dice también fines), en imponer la definición (otro sentido de finis) legítima, conocida y reconocida, de las fronteras y del territorio, en suma, el principio de división legítima del mundo social" ${ }^{\prime \prime}$.
Todo acto reconocido del derecho constitucional, es un poder simbólico fundamentado en el reconocimiento social y que por ese mismo poder omnímodo quiere dar existencia en los artículos constitucionales a lo que enuncia, acto de magia política muy análogo a la magia en las comunidades colombianas-premodernas que todavía habitan entre nosotros, es decir, aquellas que nombrando al culpable del hechizo le quitan su fuerza maligna.

En el siguiente esquema hemos seleccionado dos artículos de los 33 que se pretendieron hacer aprobar en bloque, en el proyecto de reforma constitucional de la República Bolivariana de Venezuela, el 15 de agosto de 2007, el cual era acompañado de un mico de reelección ad eternum como el que actualmente se pretende en el nuestro.

\section{Ver tabla No. 3 en la página 64}

En estos dos artículos, 11 y 16 de la Constitución Venezolana, se resume todo un proyecto de geografía política, muestra ejemplar de un optimismo y voluntarismo que sólo puede definir la visión populista del "pueblo" como "células geohumanas" del nuevo socialismo del siglo XXI.

Borrachera constitucionalista que luego de la resaca, comprueba cómo triunfa la ideología conservadora, del constituyente primario, que para bien o para mal tiene la última palabra.

El desplazamiento del poder de las personas e instituciones especializadas hacia los micro-poderes, sean éstos discursivos o bio-políticos, dispersos y

${ }^{49}$ Ibíd., pág. 89. 


\begin{tabular}{|c|c|}
\hline ARTíCULO & CONTENIDO \\
\hline 11 & $\begin{array}{l}\text { La soberanía plena de la República se ejerce en los espacios* continental e insular, lacustre y } \\
\text { fluvial, mar territorial, aéreas marítimas interiores, históricas y vitales y las comprendidas dentro de } \\
\text { las líneas de base recta que ha adoptado o adopte la República; el suelo y subsuelo de éstos; el } \\
\text { espacio aéreo continental, insular y marítimo y los recursos que en ellos se encuentran, incluidos los } \\
\text { genéticos, los de las especies migratorias, sus productos derivados y los componentes intangibles } \\
\text { que por causas naturales allí se hallen. } \\
\text { El espacio insular de la República comprende el archipiélago de Los Monjes, archipiélago de Las } \\
\text { Aves, archipiélago de Los Roques, archipiélago de La Orchila, isla La Tortuga, isla La Blanquilla, } \\
\text { archipiélago Los Hermanos, islas de situados o que emerjan del mar territorial, en el que cubre la } \\
\text { plataforma continental o dentro de los límites de la zona económica exclusiva. Sobre los espacios } \\
\text { acuáticos constituidos por la zona marítima contigua, la plataforma continental y la zona exclusiva, } \\
\text { la República ejerce derechos exclusivos de soberanía y jurisdicción en los términos, extensión y } \\
\text { condiciones que determinen el derecho internacional público y la ley. } \\
\text { Corresponde a la República derechos en el espacio ultraterrestre suprayacente y en las áreas que } \\
\text { son o pueden ser patrimonio común de la humanidad, en los términos, extensión y condiciones } \\
\text { que determinen los acuerdos internacionales y la legislación nacional.El Presidente de la República } \\
\text { podrá decretar regiones Especiales Militares con fines estratégicos y de defensa, en cualquier parte } \\
\text { del territorio y demás espacios geográficos de la República [...]. }\end{array}$ \\
\hline 16 & $\begin{array}{l}\text { El territorio nacional se conforma a los fines político-territoriales y de acuerdo con la nueva geometría } \\
\text { del poder, por un Distrito Federal en el cual tendrá su sede la capital de la República, por los Estados, } \\
\text { las Regiones Marítimas, los Territorios Federales, los Municipios Federales, y los Distritos Insulares. La } \\
\text { vigencia de los Territorios Federales y de los Municipios Federales quedará supeditada a la realización } \\
\text { de un referéndum aprobatorio en la entidad respectiva. Los Estados se organizan en municipios. } \\
\text { La unidad política primaria de la organización territorial nacional será la ciudad, entendida ésta } \\
\text { como todo asentamiento poblacional dentro del Municipio, e integrada por áreas o extensiones } \\
\text { geográficas denominadas Comunas. Las Comunas serán las células geohumanas del territorio y } \\
\text { estarán conformadas por las Comunidades, cada una de las cuales constituirá el núcleo espacial } \\
\text { básico e indivisible del Estado Socialista Venezolano, donde los ciudadanos y las ciudadanas } \\
\text { comunes tendrán el poder para construir su propia geografía y su propia historia[...]. }\end{array}$ \\
\hline
\end{tabular}


diferenciados, acertadamente en contra de la teoría marxista de concebir aparatos centralizados y monolíticos, que para Bourdieu, quien supera a Foucault en este aspecto, serán las acciones y reacciones impuestas estructuralmente, de agentes e instituciones que conforman los campos especializados, jurídicos o políticos.

Los desplazamientos del poder no tienen en cuenta los retos cruciales que las luchas históricas, racionalizan, por ejemplo, en una Constitución, a la vez que, la forma de un discurso dominante, convertido en una violencia simbólica, otra forma de poder arbitrario, sutilmente aceptado por la fuerza racional que enmascara toda codificación.

Los elementos de la geográfica política (véase los términos subrayados del esquema referido), que se quedaron únicamente en anteproyecto según el caso práctico que se tomó como referencia, prueban que una institución parlamentaria podría crear de la nada cosas o cuerpos más allá del discurso, y que parte de la omnipotencia del pensamiento constitucionalista viene a ser una forma racionalizada de dominación que ha sido matriz generativa de todas las geopolíticas del pasado y del presente.

Así, aunque toda Constitución, sea llamada fictio juris, la realidad social supera toda ficción.

\section{Conclusión}

Los geopolíticos del pasado como nuevos geógrafos de la política internacional, intentan practicar con una "ciencia espontánea" de teorías espuréas y taxonomías geográficas que cubren los espacios posibles, hasta llegar al absurdo de un rigor científico indiscutible en sus desmedidas manipulaciones de códigos

\section{Ciudadanías}

semánticos que mimetizan las ideologías más perversas y conservadoras.

Corpus y paradigmas académicos que visionan toda la política global y galáctica del nuevo príncipe del imperio de turno, promotor de profecías fundamentalistas que parecen fantasmas de la impostura de dominación, más parecidas a un acto de humor cruel sobre el hombre y las metáforas de un mundo irreal y sin sentido, que lo normalizan y normatizan bajo el manto de una política correcta, donde sólo queda la unidimensionalidad o la profecía de Orwell hecha realidad.

Por esta circunstancia nuestra reflexión sobre la geopolítica nos permite criticarla como una serie de categorías y clasificaciones subjetivas de un poder simbólico invisible pero totalizador, que como ejercicio del discurso dominante, centrado en Fictio Juris formalistas ejecuta toda una lingüística del poder simbólico.

Este estudio sólo intentó una nueva forma de llegar a comprender la genealogía del espacio como categoría que permite ver su reencauche en el macroespacio llamado Estado y luego los mecanismos criticados por Agnew, centrados en el poder, el discurso y el sujeto. Precisamente cuando abordamos a Bourdieu pudimos sobrepasar el nominalismo del poder que parece inmanente e inamovible con sus micropoderes dominantes.

La teoría de los campos político, jurídico y lingüístico fundamentan una sociología estructural que permite comprender cómo en una economía de sistemas simbólicos son los ejecutores de una muy bien elaborada nueva forma de ver la economía simbólica que va desde lo jurídico y político o viceversa, en constantes intercepciones (solapamientos) conflictivas que permiten la producción de construcciones acientíficas como la 
geopolítica clásica y las nuevas estrategias de una geografía crítica, que siguen funcionando en la cocción de un absurdo mundo global que los cartógrafos del siglo XXI y sus "ciencias rigurosas" quieren anunciar y terminar como fin de toda la historia y hacerla coincidir con la extensión de su nuevo Atlas Google Earth, donde se quiere hacer ver en tercera dimensión y GPS que el mapa del nuevo imperio global tiene el tamaño real del imperio, coincidiendo punto a punto, pixel a pixel, con el tamaño real del nuevo ordenamiento global. [

\section{Bibliografía}

AGNEW, John, Geopolítica: Una revisión de la política mundial, Madrid, Trama Editorial, trad., Maria D. Lois, 2005.

BACHELARD, Gastón, Epistemología. Textos escogidos por Dominique Lecourt, Barcelona, Editorial Anagrama, trad., Elena Posa, 1973.

, La poética del espacio, México, F.C.E., trad., Ernestina de Champourcin, 2006.

BADIE, Bertrand, Un mundo sin soberanía. Estados entre artificio y responsabilidad, Bogotá, Universidad Externado de Colombia, Tercer Mundo Editores, 2000.

BELL, Daniel, El advenimiento de la sociedad postindustrial. Un intento de prognosis social, Madrid, Alianza editorial, 1976.

BORGES, Jorge Luis, Historia Universal de la infamia, Barcelona, Plaza \& Janes, 1985.

BOURDIEU, Pierre, "Espíritus de Estado. Génesis y estructura del campo burocrático", en: Revista Sociedad, de la Facultad de Ciencias Sociales(UBA), 1993.

, "La nueva Vulgata planetaria", en: Revista Colombiana de Educación, Número especial en memoria de Pierre Bourdieu, Bogotá, U. Pedagógica Nacional, No. 42, 2002.

Sobre el poder simbólico, en Intelectuales, política y poder, Buenos Aires, Editorial Universitaria de Buenos Aires, trad. Alicia Gutiérrez, 5a reimpresión, 2006. 
- Espacio social y poder simbólico en cosas dichas, Gedisa, Buenos Aires, 1988.

¿Qué significa hablar? Economía de los intercambios lingüísticos, Madrid, Akal, 1985.

\section{Anagrama, 1999.}

Meditaciones pascalianas, Barcelona, Editorial

BRZEZINSKI, Zbigniew, La era tecnotronica, [Between Two Ages. America's Role in the Technetronic Era ], Buenos Aires, Editorial Paidos, 1970.

El gran tablero mundial. La supremacía Estadounidense y sus imperativos geoestratégico, Barcelona, Editorial Paidos, 1998.

CASTELLS, Manuel, "La era de la información. Economía, sociedad y cultura", en: La sociedad red, Vol. I, Siglo XXI, México, 2a Ed., 2000.

DELEUZE, Gilles, GUATTARI, Félix, El Antiedipo, Capitalismo y esquizofrenia, Barcelona, Barral Editores, 1974.

FERNÁNDEZ, J. Manuel, "La noción de violencia simbólica en la obra de Pierre Bourdieu: una aproximación crítica", en: Cuadernos de trabajo social, Madrid, Universidad Complutense de Madrid, Vol. 18, 2005.

FOUCAULT, Michael, La gubernamentalidad en Espacios de poder, Lección en el Colegio de Francia en enero de 1978, Madrid, Ediciones Endymion, 1991.

GÓMEZ, Lucía, Procesos de subjetivación y movimiento feminista. Una aproximación política al análisis de la identidad contemporánea, España, Universidad de Valencia, Tesis doctoral, 2003.
GUTIÉRREZ, Alicia, Las prácticas sociales: una introducción a Pierre Bourdieu, Argentina, Ferreyra Editor, Córdoba, 2005.

MAQUIAVELO, Nicolás, El Príncipe, Madrid, Editorial Sarpe, trad., Ángeles Cardona, 1983.

MONCAYO, Víctor Manuel, El Leviatán derrotado. Reflexiones sobre teoría del Estado y el caso colombiano, Bogotá, Grupo Editorial Norma, 2000.

MORALES de SETIEN RAVINA, Carlos, "La racionalidad jurídica en crisis: Pierre Bourdieu y Günther Teubner", en: La fuerza del derecho, Bogotá, Ediciones Uniandes, Universidad Javeriana, Siglo del Hombre Editores, $2^{a}$ reimpresión, 2005.

NEGRI, Toni y HARDT, Michael, Imperio, Ediciones desde abajo, trad., Eduardo Sadier, 2001.

POLANYI, Karl, El sustento del hombre, Barcelona, Biblioteca Mondadori, 1994.

SANDOVAL, Mary Luz, Diacrítica del terror .Terrorismo y antiterrorismo a la luz del pensamiento de Pierre Bourdieu, Bogotá, Tercer Mundo Editores, 2007.

TAYLOR, Peter, Geografía política. Economía Mundo, Estado-nación y Localidad, Madrid, Trama Editorial, trad., Adela Despujol y Cairo Carou, 1994.

TELLEZ, Gustavo, Pierre Bourdieu., Conceptos básicos y construcción socioeducativa. Claves para su lectura, Bogotá, Universidad Pedagógica Nacional, 2002. 